\title{
Award 2012
}

International Confederation of

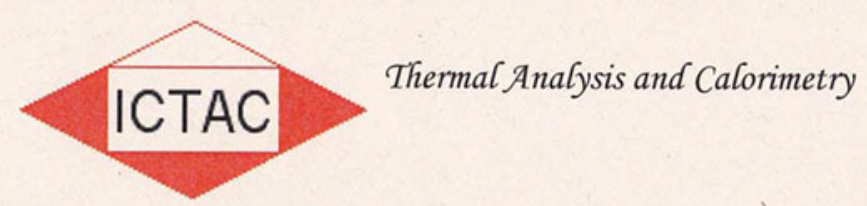

\section{The ICTAC Distinguished Service Award}

was presented, on proposal of the ICTAC Executive, to

\section{Dr. Judit SIMON}

Editor-in-Chief of the Journal of Thermal Analysis and Calorimetry, for her long-lasting service to the community of Thermal Analysis and Calorimetry and for her continuing action to save and increase the standards of publication in this field

on the $21^{\text {st }}$ August 2012, in Osaka, Japan

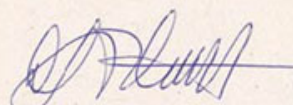

Dr. Don Burlett, President of ICTAC

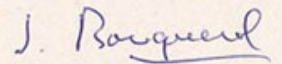

Dr. Jean Rouquerol, Past-President 